
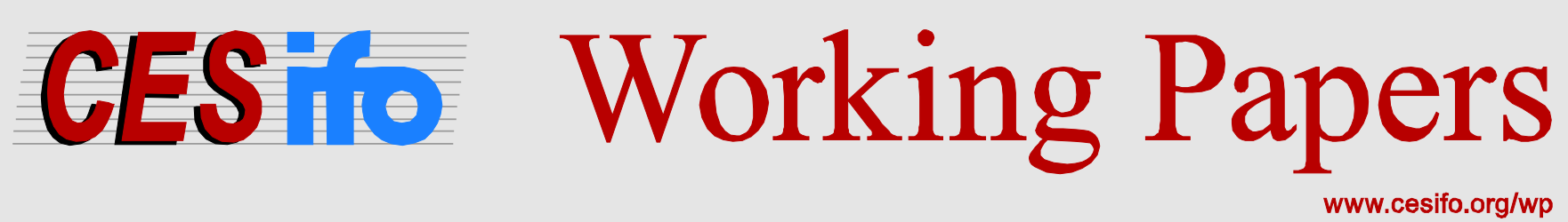

\title{
Vertical Integration and Downstream Collusion
}

\author{
Sara Biancini \\ David Ettinger
}

CESIFO WORKING PAPER NO. 5933

CATEGORY 11: INDUSTRIAL ORGANISATION

JUNE 2016

Presented at CESifo Area Conference on Applied Microeconomics, March 2016

An electronic version of the paper may be downloaded
- from the SSRN website: $\quad$ www.SSRN.com
- from the RePEc website:
- from the CESifo website: 


\title{
Vertical Integration and Downstream Collusion
}

\begin{abstract}
We investigate the effect of a vertical merger on downstream firms' ability to collude in a repeated game framework. We show that a vertical merger has two main effects. On the one hand, it increases the total collusive profits, increasing the stakes of collusion. On the other hand, it creates an asymmetry between the integrated firm and the unintegrated competitors. The integrated firm, accessing the input at marginal cost, faces higher profits in the deviation phase and in the non cooperative equilibrium, which potentially harms collusion. As we show, the optimal collusive profit-sharing agreement takes care of the increased incentive to deviate of the integrated firm, while optimal punishment erases the difficulty related to the asymmetries in the non cooperative state. As a result, vertical integration generally favors collusion.
\end{abstract}

JEL-Codes: D430, L130, L400, L420.

Keywords: vertical integration, tacit collusion.

Sara Biancini

University of Caen-Normandie

CREM

Caen / France

sara.biancini@unicaen.fr
David Ettinger

University Paris-Dauphine

PSL, LEDa \& CEREMADE

Paris / France

david.ettinger@dauphine.fr

May 2016

We would like to thank Andrea Amelio for many discussions that inspired this paper. We also thank Régis Renault, Laurent Linnemer and seminar participants at Oligo Workshop in Madrid, EARIE 2015 and CESIfo Area Conference in Applied Economics 2016 for their comments. 


\section{Introduction}

The economics of vertical mergers have gained increasing attention in the last decades. Whereas the classic results of the Chicago school critique, starting from Stigler (1964), had created a prior of non harmfulness of vertical integration, the more recent contributions have raised attention on its anticompetitive effects (see Riordan, 2008 for a review of this literature). The post-Chicago scholar have raised several objections to the Chicago school view, showing first that vertical integration can produce foreclosure raising-rival's-costs (Ordover, Saloner, and Salop, 1990) and second that vertical integration can help restoring monopoly power when an upstream monopoly initially lacks the necessary commitment to extract full monopoly rents (Rey and Tirole, 2007).

Starting from the raising-rival's-costs result, Chen (2001) shows that vertical integration can also induce independent downstream firms to be willing to contract with the integrated supplier at a supra-competitive price, softening downstream competition. As a result, vertical integration allows the realization of a collusive outcome. Chen and Riordan (2007) develop this line of research, showing that vertical integration can help an upstream firm to cartelize the downstream market via exclusive contracts with the other downstream providers.

This first stream of literature took a static view of the interaction between firms. In contrast, a vertical merger may have a potential anticompetitive effect because it facilitates the emergence of a collusive agreement when upstream and downstream firms interact repeatedly. The main theoretical contribution in this sense is Nocke and White (2007). They look at the possibility that vertical integration facilitate upstream collusion in a repeated games framework. In their model, vertical integration has both an "outlet effect" (foreclosing part of the downstream market) and a punishment effect (integrated firms typically make more profit in the punishment phase than unintegrated upstream firms). The main result of the paper, obtained under two-part tariffs, is that the outlet effect always outweighs the punishment effect and vertical integration unambiguously facilitates collusion. Normann (2009) independently derived similar results in a model with linear tariffs. When two-part tariffs are not available, in the absence of integration upstream collusion does not guarantee maximal profits, because of double marginalization. Thus, the overall welfare balance of vertical integration is not necessarily negative. The integrated firm serves its downstream unit at marginal cost, and the elimination of the double markup can imply a welfare gain. However, as in Nocke and White (2007) vertical integration 
can expand the values of the discount factor for which collusion is feasible, thus creating new opportunities of collusion and potentially reducing welfare.

We also investigate the impact of vertical mergers in a dynamic game of repeated interaction between upstream and downstream firms, but, contrarily to Nocke and White (2007) and Normann (2009), we concentrate on downstream collusion. The possibility of downstream collusion in vertical related industries has been studied in Piccolo and Miklós-Thal (2012). They consider vertical chains under exclusivity contracts and show that collusion on supply contracts, consisting in above marginal cost pricing plus a negative fee (slotting alliance) can increase collusion. In our paper, we do not assume vertical chains (downstream firms are not linked to one unique upstream supplier) and we introduce the possibility of a vertical merger. This possibility has been neglected by the existing literature, with the exception of Mendi (2009) who considers a competitive upstream industry and a downstream duopoly. Downstream firms have asymmetric costs. In this context, the author shows that vertical integration can help sustaining collusion under cost asymmetries, allowing for implicit side-transfers. We consider a similar problem, but we do not restrict the downstream market to be a duopoly and we do not impose asymmetric costs for downstream firms. In addition, we assume that the upstream market is also oligopolistic. We thus have two vertically related oligopolies. Downstream firms are ex-ante symmetric but backward integration creates a cost asymmetry: the integrated firm has access to the input at a lower cost. Moreover, we do not restrict the attention to Nash reversion, but following we consider optimal punishment strategies: when a firm deviates from the collusive agreement, all firms suffer maximal punishment (this is in line with the optimal punishments proposed in Abreu, 1986, 1988 and more recently applied to an asymmetric oligopoly problem by Miklos-Thal, 2011).

Under our assumptions, we show that vertical integration generally favors collusion, decreasing the critical discount factor above which collusion is feasible. Vertical integration generates a trade-off. On the one hand, it allows downstream firms to have access to the input at a lower price, removing the upstream oligopolistic margin. On the other hand, vertical integration creates an asymmetry which is potentially harmful for collusion. The vertically integrated firm has a higher incentive to deviate both from the collusive agreement and from the defined behavior in the punishment phase (because it has unlimited access to the intermediate good at marginal cost). As we show, the optimal collusive agreement solve these two asymmetries. The 
asymmetry in the punishment phase is balanced by allocating asymmetric shares of the collusive profit to the integrated and non integrated firms, and the asymmetry in the punishment phase is solved by enforcing maximal punishment in case of deviation from the collusive agreement. For this reason, ex-post cost asymmetries are not an obstacle to collusion.

The paper proceed as follows. Section 1.1 describes the current views about vertical integration and collusion as expressed in the US and EU merger policy and law. Sections 2 and 3 present the model and the main results. Section 4 concludes.

\subsection{Coordinated effects of vertical integration and merger policy}

Both the US and the EU merger policies embrace the idea that vertical mergers might give rise to anti-competitive effects due to coordinated effects. The US Non-Horizontal merger guidelines, adopted in 1984, mainly identify two mechanisms in which a vertical merger can give rase to collusion in the upstream market. First, it states that " $A$ high level of vertical integration by upstream firms into the associated retail market may facilitate collusion in the upstream market by making it easier to monitor price." Second, it also argues that "The elimination by vertical merger of a particularly disruptive buyer in a downstream market may facilitate collusion in the upstream market. If upstream firms view sales to a particular buyer as sufficiently important, they may deviate from the terms of a collusive agreement in an effort to secure that business, thereby disrupting the operation of the agreement. The merger of such a buyer with an upstream firm may eliminate that rivalry, making it easier for the upstream firms to collude effectively.". The more recent EU Non-Horizontal merger guidelines adopted in 2008 expand the set of instances in which a vertical merger can result in coordinated effects and state that " $A$ vertical merger may make it easier for the firms in the upstream or downstream market to reach a common understanding on the terms of coordination". Our paper sheds light on how a vertical merger can lead to coordinated effects in the downstream market.

However, the paucity of vertical mergers analyzed using a coordinated effect theory by both EU and US antitrust authorities shows a certain degree of discomfort in bringing those cases. In the US the main cases are GrafTech/Seadrift, Merk/Medco and Premdor/Masonite. In the Merk/Medco and GrafTech/Seadrift cases, the Federal Trade Commission (FTC) appeared mainly concerned with the possibility of collusion among symmetrically vertical integrated competitors and upstream coordination. In this context, the FTC evoked the risks associated with the fact that the merged entity will be able to monitor the commercial terms of upstream trans- 
actions thus "facilitating" tacit understanding. In the Premdor/Masonite case, the downstream collusion potential (neglected in the guideline) is explicitly evoked. The FTC explains that vertical integration is likely to conceal the incentives of an upstream firm to disrupt downstream collusion expanding the offer to non-colluding downstream competitor. In the EU, the most relevant cases come from the energy sector: Shell/DEA (Case COMP/M.2389) and BP/EO (Case COMP/M.2533). The Commission explicitly lists in the decisions "retaliation possibilities" as an element that should be taken into account to establish collective dominance. It also mentions that integrated undertakings can use the "tacit allocation of contracts" as a mean to increase collusion. The Commission also indicates the disappearance of an independent upstream supplier as a source of concern. More importantly, the Commission states that vertically integrated entities are likely to acquire through the merger "sufficient means of retaliation" to enforce collusion. As the FTC, the EU Commission seems mainly concerned with the incentive to collude of vertically integrated firms with other vertically integrated ones. As we show in our model, increased retaliation possibilities can indeed increase the collusion potential also with downstream independent competitors. In principle, privileged access to an upstream producer can both increase the retaliation possibility of the integrated firm, as well as its incentive to disrupt collusion. Our model illustrates the theoretical arguments for which there are reason to think that the pro-collusive effect of a vertical merger would generally prevail.

\section{The model}

We consider an industry with vertically related firms, $M \geq 2$ upstream firms denoted $U_{1}, \ldots, U_{M}$ and $N \geq 2$ downstream firms denoted $D_{1}, \ldots, D_{N}$. Upstream firms produce an intermediate good which is necessary for the production of the final good by downstream firms. The intermediate good is uniquely used by these downstream firms (no alternative market).

There is no fixed production cost. Any upstream firm $U_{i}$ has a constant marginal cost for producing the intermediate good, $c_{i}$. For the sake of simplicity, we order upstream firms so that for any $i<M, c_{i} \leq c_{i+1}$. We assume that $0<c_{1}<c_{2}$ and denote $C$ the vector of marginal costs of size $M$.

In order to produce one unit of the final good, a downstream firm needs one unit of the intermediate good. We assume that the only cost that downstream firms face is the amount paid for the units of the intermediate good, normalizing other downstream costs to zero.

Neither upstream nor downstream firms have capacity constraints. 
Units of the final good are sold to final consumers who consider them as homogenous. Consumers are characterized by a demand function $Q(p)$. There is a maximal price $\bar{p}>c_{2}$ such that $Q(\bar{p})=0$ and for any $p<\bar{p}, Q(p)>0$. $Q$ is strictly decreasing on $[0, \bar{p})$, twice differentiable and for all $x \in[0, \bar{p}],(p-x) Q(p)$ is strictly concave on $[x, \bar{p})$. This ensures that the monopoly price on the downstream market, $p_{c}^{m}$, is well defined and increasing in the constant unit cost $c$.

We also assume that the differences between upstream firms are limited so that $p_{c_{1}}^{m}>c_{2}$ and $\left(x-c_{1}\right) Q(x)$ is strictly increasing on $\left[c_{1}, c_{2}\right]$.

In the markets for the intermediate and for the final good, firms compete in price with linear prices (Bertrand competition). We denote $w_{i}$ the price offer of the upstream firm $i$ and $p_{j}$, the price offer of downstream firm $j$ to consumers.

At any period of the game, firms play the following stage game.

- Stage 1: Upstream firms simultaneously make a public offer: a unit price $w_{i}$ from upstream firm $i$ to any downstream firm for units which can only be bought and used during this period of the game. ${ }^{1}$

- Stage 2: Each downstream firm chooses one or several proposals of the upstream firms without specifying the precise quantity it will buy. It will be determined later by the Bertrand game on the downstream market.

- Stage 3: Downstream firms simultaneously make price offers to consumers for the final goods.

- Stage 4: A quantity $Q(\underline{p})$ of the final good is sold to consumers with a price $\underline{p}=\min _{j} p_{j}$, the final good price. If only one firms proposes price $\underline{p}$, it sells the whole quantity $Q(\underline{p})$. In case of tie, if there is no specific agreement among firms having proposed the lowest price, the demand is split between the firms having proposed price $\underline{p}$ in any way consistent with the equilibrium (no firm has an incentive to deviate to a different price). The firms having proposed a price equal to $p$ may also jointly decide of an allocation of the total quantity among themselves (market sharing agreement). Any agreement can be sustained as long as the total quantity is equal to $Q(p)$ and all quantities are weakly positive.

- Stage 5: Downstream firms who sold units to consumers pay the units of the intermediate good they bought to their suppliers, choosing freely how to share the total quantity among

\footnotetext{
${ }^{1}$ We don't allow for storage capacities to avoid additional interdependence across periods which would make the game much more complex. For instance, firms' actions would depend on the anticipation of all future prices of the intermediate good, making the game hardly tractable.
} 
their suppliers.

In the model, the upstream firms make their offers to downstream first so that downstream firms are aware of their costs before proposing prices to final consumers. However, the quantity of intermediate goods bought is fixed only once the downstream market is organized. This setting will also allow to represent collusion between an integrated firm and downstream firms since the integrated firm can commit to sell the intermediate good at a specific (low ?) price before the other downstream firms, members of the cartel, make a price proposal to final consumers.

The game consists in an infinite repetition of the stage game. Firms maximize the discounted sum of stage game payoffs with a common discount factor $\delta \in(0,1)$. At the end of a period of the game, all the decisions of the players are perfectly observed by all the players (perfect monitoring). If a firm is vertically integrated, it maximizes the joint profit of its upstream and its downstream branch. This means that in stage 1, the upstream branch of the integrated firm makes an offer to the downstream branch at a price equal to its marginal cost.

Since we focus on the effect of vertical integration on downstream collusion, we assume that a vertical merger does not affect the cost functions of the firms. ${ }^{2}$

We focus on the effects of vertical integration on the feasibility of collusion, investigating whether a vertical merger increases the capability of firm to sustain a tacit collusion agreement or not. For this reason, our object of interest is the critical threshold of the discount factor, $\underline{\delta}$, such that collusion is sustainable if and only if firms' discount factor is larger than this threshold.

We denote $V_{i}^{\text {col }}$ the present value of collusive profits and $V_{i}^{\text {pun }}$ the present value of punishment profits, while $\pi_{i}^{d}$ is the period payoff from a deviation. Collusion is sustainable if the following incentive compatibility constraint is satisfied:

$$
V_{i}^{c o l}(\delta) \geq \pi_{i}^{d}+\delta V_{i}^{\text {pun }}(\delta)
$$

The critical discount factor $\underline{\delta}$ is determined by the incentive compatibility constraints of each firms, given by (1). There exists a collusive equilibrium in which downstream firms sell at the collusive price ${ }^{3}$ if and only if $\delta>\underline{\delta}$. If $\underline{\delta}$ is lower (resp: higher) with vertical integration than without it, we will say that vertical integration raises (resp: reduces) collusion opportunities. We will denote, $\underline{\delta}^{N I}$ and $\underline{\delta}^{I}$, the critical collusive discount factor without integration and with

\footnotetext{
${ }^{2}$ However, assuming that vertical integration reduces the marginal cost for producing the intermediate good would not affect the result as long as the upstream branch of the integrated firm has the lowest marginal cost for producing the intermediate good. Indeed, the lower marginal cost of the integrated firm could alternatively be interpreted as the efficiency effect of the merger.

${ }^{3}$ Considering the best offers of upstream firms as their joint cost function.
} 
integration respectively.

\section{The Analysis}

\subsection{No vertical integration}

To analyze the benchmark case of no vertical integration, we rely on a standard representation of a collusive agreement in a repeated game framework. If downstream firms form a cartel, they jointly fix a collusive price. A firm starts charging this price and does it at each period if all the other firms do the same. If one firm deviates, this triggers a punishment phase in which downstream firms play the Bertrand static equilibrium in all subsequent periods. The repeated game has an infinity of collusive equilibria but we focus on collusive equilibria in which downstream firms obtain the highest total profit. We can show that the vertical dimension of the situation does not affect much the conditions for the existence of collusion in the downstream market. The critical collusive discount factor coincides with what we observe in a vertically unrelated market where firms have an identical constant marginal cost.

Result 1 Without vertical integration, $\underline{\delta}^{N I}=\frac{N-1}{N}$.

The intuition for this result is as follows. When downstream firms collude, they all buy the intermediate good at the lowest upstream price $\underline{w}$ and set a price equal to $p_{\underline{w}}^{m}$. They equally share a total profit equal to $\pi_{\underline{w}}^{m}$ so that each downstream firm obtains $\frac{\pi_{w}^{m}}{N(1-\delta)}$ if they cooperate. If a downstream firm deviates, she can propose a price arbitrarily close to $p_{\underline{w}}^{m}$ and obtain a revenue arbitrarily close to $\pi_{\underline{w}}^{m}$. However, in all the following periods, at least two downstream firms will choose a price equal to $\underline{w}$ so that no downstream firm will make any profit. The continuation payoff after any deviation is equal to zero. Hence the minimum value of the discount factor, $\underline{\delta}^{N I}$, above which collusion is sustainable must be such that the cooperation profit $V^{c o l}=\frac{\pi_{w}^{m}}{N(1-\underline{\delta})}$ is equal to the deviation profit: $\pi_{i}^{d}=\pi_{\underline{w}}^{m}$ (the punishment profit is $V_{i}^{\text {pun }}=0$ ). Hence, the incentive compatibility constraint (1) determines the threshold discount factor: $\frac{\pi_{w}^{m}}{N\left(1-\underline{\delta}^{N I}\right)}=\pi_{\underline{w}}^{m}$ so that $\underline{\delta}^{N I}=\frac{N-1}{N}$.

Let us also note that, even if we consider downstream collusion on a different price, lower than $p_{\underline{w}}^{m}$, the lowest $\delta$ allowing collusion remains equal to $\frac{N-1}{N}$ since we can apply exactly the same reasoning. The collusion profit for any downstream firm is $\frac{\pi^{c o l}}{N(1-\delta)}$, the deviation profit is arbitrarily close to $\pi^{c o l}$ and firms make zero profits in the periods following a deviation. 


\subsection{Vertical integration}

We assume that $U_{1}$ and $D_{1}$ merge to create $I_{1} \cdot{ }^{4}$ Before analyzing this situation, we need to specify our representation of competition and collusion in this case.

First, the integrated firm, $I_{1}$. Its profit is equal to the sum of the profits of $U_{1}$ and $D_{1}$. Besides, we assume that $D_{1}$ always has the possibility to buy an unlimited quantity of intermediate goods to $U_{1}$ at a price equal to $c_{1}$.

Second, the other competitors. As long as there is no collusion, their situation is not modified. In case of collusion between downstream firms, we assume that in period 1 of the stage game, in addition to the public offers, the integrated firm can make a private offer to downstream firm $j$ at a price $w_{j}^{c}$ per unit for a maximum quantity $\underline{q}_{j}$ of intermediate goods. In period 2, in addition to public offers, downstream firms may accept or refuse the private offer made by the integrated firm (if such an offer has been made in period 1).

Now, we see that the vertical merger has two effects. First, it creates an asymmetry among downstream firms. $D_{1}$ has a direct access to intermediate goods at a lower price than other firms. As any asymmetry, this does not favor cooperation among downstream firms. Second, if downstream firms cooperate, $D_{1}$ can share its access to cheaper intermediate goods with the other members of the cartel so that the total cartel profit can be higher (equal to the monopoly profit with a marginal $\operatorname{cost} c_{1}$ ). This increase in the surplus created by the cartel favors collusion. We will show that the second effect is always stronger than the first one.

Proposition 1 The critical collusive discount factor is strictly lower with vertical integration than without integration, $\underline{\delta}^{I}<\underline{\delta}^{N I}$.

Proof: see in the appendix

Corollary 1 Vertical integration facilitates downstream collusion.

The intuition for the result in Proposition 1 is the following. As already mentioned, a merger increases total industry profits under collusion. In addition, the merger makes firms asymmetric. Despite this asymmetry, after a deviation, firms can be made symmetric by a maximal punishment scheme which set all the continuation payoff to zero. This is straightforward for non integrated firms $D_{j}$ with $j \neq 1$. For instance, maximal punishment can be obtained if,

\footnotetext{
${ }^{4}$ If another upstream firm rather than $U_{1}$ merges with a downstream firm, this will not affect the competition outcome.
} 
after a deviation, firms play the static Bertrand game with price equal to $c_{2}$ (and firm $I_{1}$ serves all the market). But we can also build equilibrium strategies such that $I_{1}$ 's continuation payoff is equal to zero after a deviation, thus ensuring maximal punishment to the integrated firm. After a deviation by $I_{1}$, in all the posterior periods, the integrated firm and a competitor, say firm $d_{2}$, set $p_{1}=p_{2}=c_{1}$ and all other downstream competitors set a higher price, while the allocation rule is such that firm $I_{1}$ serves all the market. ${ }^{5}$ Under this scheme, if profit shares where allocated symmetrically in the collusion phase, the situation would be exactly the same for $D_{1}$ as in the case without vertical integration (except that the cost of the intermediate good decreased from $c_{2}$ to $c_{1}$ ). $I_{1}$ would obtain a fraction $\frac{1}{N}$ of the collusive profit in all the periods of cooperation, the whole profit in deviation and nothing after the first period of deviation. Therefore, with symmetric profit shares, the critical collusive discount factor would be exactly the same as without vertical integration for $D_{1}$. However, upon a merger, firms become asymmetric also in the deviation phase. On the other hand, when deviating, other firms have to resort to alternative suppliers to buy the extra units, at a price at least equal to $c_{2}$ (no upstream firm would propose a price strictly lower than $c_{2}$ ). Thus, if firms insist in symmetric profit shares, the critical discount rate for the non integrated firms would now be strictly lower than the one without vertical integration. Thus, firms can decrease the critical discount factor for the integrated firm and increase the one for the non integrated competitor, by sharing profits asymmetrically in the collusive case, i.e. allocating a higher share of the profits to the integrated firm. Because the cost of a deviation is now strictly higher for the non-integrated competitors, starting from a symmetric profit allocation it is always possible to increase the market share of $D_{1}$ and decrease the market share of the competitors in a way that allows to find a common critical discount factor which is lower than $\delta^{N}$.

\section{Imperfect collusion.}

As shown in Section 3.1, in the absence of vertical integration the critical threshold $\underline{\delta}^{N I}$ does not depend on the chosen collusive price. We now consider the creation of a collusive cartel among downstream firms choosing a price lower than $p_{c_{1}}^{m}$ under vertical integration.

\footnotetext{
${ }^{5}$ The described strategies allow firms inflict maximal punishments in case of any deviation. This strategy is optimal and maximizes the scope of collusion. To do this, they require at least one firm to play a weakly dominated strategy in the one-shot game. Nonetheless, the idea that firms can coordinate on punishments that are harsher than usual grim-trigger strategies is now standard in the literature. Maximal punishment of the most efficient firm can also be obtained using a stick and carrot punishments which involves below cost pricing for this firm for a finite number of periods (a finite "price war"). It seems resonable to think that firms are able to enforce harsh punishment schemes if they constitute an equilibrium.
} 
Proposition 2 With vertical integration, for any value of $\delta>0$, there exists a constant collusive equilibrium with a collusive price, $p^{c o l} \in\left(c_{2}, p_{c_{1}}^{m}\right)$.

Proposition 3 With vertical integration, as $\delta$ becomes smaller, the maximum constant collusive price that can be sustained get closer to $c_{2}$ (the non collusive price).

Proof: see in the appendix.

We define here a constant collusive equilibrium as a collusive equilibrium in which collusive firms behave the same way during all collusive periods. The constant collusive price is the price at which the final good is sold during all the periods in this constant collusive price.

The intuition for Propositions 2 and 3 is the following. From Proposition 1 we know that upon vertical integration, it is possible to decrease the critical discount factor of collusion by allocating a smaller market share to the non integrated firm, because their gains from deviations are smaller than the one obtained by firm $D_{1}$. This asymmetry in deviation incentives is larger when the price is closer to $c_{2}$. Thus, when the collusive price $p^{\text {col }}$ becomes closer to $c_{2}$, it is possible to raise $\alpha$ closer to 1 so that all firms stick to the collusive equilibrium. However, to enforce collusion when $\delta$ becomes smaller, the collusive price must get closer to $c_{2}$ (the non collusive price), so that the market power distortion related to collective dominance vanishes when $\delta$ goes to zero.

Welfare Analysis. Because $c_{1}<c_{2}$, vertical integration can avoid double marginalization, which increases productive efficiency. Nonetheless, we have also shown that vertical integration creates new collusion opportunities, expanding the range of the discount factor for which collusion is sustainable. When collusion is created by vertical integration, the price increases from the competitive Bertrand price $c_{2}$ to the monopoly price, which is strictly larger, thus decreasing welfare.

Corollary 2 If downstream firms always collude in a way which maximizes their joint profit whenever it is possible, for all $\delta \leq \frac{N-1}{N}$ vertical integration decreases welfare and for all $\delta>\frac{N-1}{N}$ vertical integration increases welfare.

If $0<\delta<\frac{N-1}{N}$, without vertical integration, there is no collusive equilibrium and the price is equal to $c_{2}$. With vertical integration, there always exists a collusive equilibrium in which the final price is strictly higher than $c_{2}, c_{2}$ being the price without collusion. If $\delta>\frac{N-1}{N}$, 
with or without vertical integration, a collusive equilibrium exists and the price is lower with vertical integration since it is equal to the monopoly price with a marginal cost of $c_{1}$ rather than the monopoly price with a marginal of $\operatorname{cost} c_{2}$. The integration allows to avoid double marginalization.

The welfare effect of a vertical merger is thus ambiguous. It increases efficiency by lowering the price of the intermediate good, but it possibly increases market power through collective dominance lowering the critical discount factor. It is important to note that Result 2 depends on the fact that we have assumed that firms sustain the collusive outcome which gives them the highest possible profit (when there exists a collusive equilibrium). Vertical integration is welfare decreasing for $0<\delta<\frac{N-1}{N}$ because it creates new collusion opportunities and we do not allow the efficiency effect to be large enough to lead to lower prices (i.e. we restrict our attention to the case $c_{2} \leq p_{c_{1}}^{m}$ ).

\section{Nonlinear upstream tariffs.}

We have assumed so far that upstream firms charge linear tariffs for the intermediate good. We now consider the possibility of nonlinear tariff.

In the vertical integration case, the possibility to use nonlinear upstream tariffs only enlarges the toolkit for collusion. Besides, even without non linear upstream tariffs, we considered optimal punishment in which the deviating firm has a profit equal to zero in the following periods. Therefore, adding the possible use of nonlinear upstream tariffs cannot increase the critical discount factor in case of vertical integration.

Now, without vertical integration, we can show that the possibility to use nonlinear upstream tariffs cannot decrease the critical discount threshold, $\delta^{N I}$. Hence, the main result that vertical integration generally helps to sustain collusion is preserved.

The intuition for the non decreasing effect of nonlinear tariffs on $\delta^{N I}$ is as follows. When there is no vertical merger and no collusion, a two part tariff cannot increase the upstream profits, because of downstream Bertrand competition. On the other hand, when downstream firms collude, the most efficient upstream firm $U_{1}$ could increase its profits proposing a nonlinear tariff. Suppose first that the tariff is a classic two-part tariff (a unit price $w$ plus a fixed fee $T$ ). In this case, the best contract that $U_{1}$ can propose is a linear fee $w=c_{1}$ and $T=\frac{1}{N}\left(\pi_{c_{1}}^{m}-\pi_{c_{2}}^{m}\right)$. Such a $T$ is the maximum fixed fee that the upstream $U_{1}$ can extract without inducing downstream firms to choose an alternative upstream provider. In this case the collusive profits left to the downstream firms are the same as with linear tariffs $\left(\frac{1}{N} \pi_{c_{2}}^{m}\right)$, but the deviation profits are higher 
(because the marginal unit can be bought at $c_{1}$ ). As a result, the critical discount factor above which collusion is feasible is larger than $\delta^{N I}$. Then, two-part tariffs makes collusion under the benchmark case of no merger even more difficult, reinforcing our result.

One may note that this type of two-part tariff might be undesirable for the upstream firm if (this is the case if it breaks the downstream cartel and the profit obtainable trading with a downstream cartel, i.e. $\pi_{c_{1}}^{m}-\pi_{c_{2}}^{m}$ is greater than the one obtained by the upstream firm when there is competition downstream, i.e. $\left.\left(c_{2}-c_{1}\right) Q\left(c_{2}\right)\right)$. In this case, we can imagine that the upstream firm might propose a more complicated nonlinear tariff, for instance a tariff with two

kinks of the type $w=c_{1}$ and $T=\frac{1}{N}\left(\pi_{c_{1}}^{m}-\pi_{c_{2}}^{m}\right)$ for quantities $q_{i} \leq \frac{1}{N} Q^{M}\left(c_{1}\right)$, and a linear tariff $w=c_{2}$ otherwise. If the upstream firm is able to do this, the critical discount factor for downstream collusion with upstream nonlinear tariff is the same than under linear tariff.

It is also worth noting that the presence of nonlinear tariffs solve the double marginalization problem in the case of absence of vertical integration. Thus, with nonlinear tariff, for values of the discount factor such that collusion is sustainable both with and without vertical integration, the vertical merger has no impact on welfare.

\section{Conclusion}

The paper shows that in a simple double oligopoly context vertical integration generally increases the feasibility of downstream collusion. Using maximal punishments firms can enforce a collusive outcome more easily when a vertical integration takes place. As such, our results contribute to the debate on coordinated effects of mergers. In this context, the analysis of factors which facilitates collusion is meant to inform merger policy decisions. For instance, the European merger guidelines recognize that evidence of past coordination is an important element when evaluating the coordinated effect of merger. Similarly, the US guidelines indicate past price wars as a possible indicators of failed attempts to collude. Our analysis shows that a vertical merger can be a way for firms to increase the feasibility of collusion in these markets. As such, it should be taken into account when attempting to establish if a merger is likely to create or strengthen collusion in a market. The welfare effect of vertical integration is generally ambiguous. However, our framework allows to identify instances in which a vertical merger, creating new collusion opportunities, has a welfare reducing effect. 


\section{References}

Abreu, D. (1986). Extremal equilibria of oligopolistic supergames. Journal of Economic Theory $39(1), 191-225$.

Abreu, D. (1988). On the theory of infinitely repeated games with discounting. Econometrica: Journal of the Econometric Society, 383-396.

Chen, Y. (2001). On vertical mergers and their competitive effects. RAND Journal of Economics, 667-685.

Chen, Y. and M. H. Riordan (2007). Vertical integration, exclusive dealing, and expost cartelization. The Rand Journal of Economics 38(1), 1-21.

Mendi, P. (2009). Backward integration and collusion in a duopoly model with asymmetric costs. Journal of Economics 96(2), 95-112.

Miklos-Thal, J. (2011). Optimal collusion under cost asymmetry. Economic Theory 46(1), 99-125.

Nocke, V. and L. White (2007). Do vertical mergers facilitate upstream collusion? American Economic Review 97(4), 1321-1339.

Normann, H.-T. (2009). Vertical integration, raising rivals' costs and upstream collusion. European Economic Review 53(4), 461-480.

Ordover, J. A., G. Saloner, and S. C. Salop (1990). Equilibrium vertical foreclosure. The American Economic Review, 127-142.

Piccolo, S. and J. Miklós-Thal (2012). Colluding through suppliers. The RAND Journal of Economics 43(3), 492-513.

Rey, P. and J. Tirole (2007). A primer on foreclosure. Handbook of industrial organization 3, $2145-2220$.

Riordan, M. H. (2008). Competitive effects of vertical integration. Handbook of Antitrust economics, 144-182.

Stigler, G. J. (1964). A theory of oligopoly. The Journal of Political Economy, 44-61. 


\section{Appendix A1: Proof of Proposition 1}

Let us consider the following collusive agreement.

In stage $1, U_{1}$ makes a secret proposal to other downstream firms, selling to each of them a quantity $\frac{1-\varepsilon}{N} q_{c_{1}}^{m}$ (with $\varepsilon>0$ and arbitrarily small) at a price $c_{1}$ and a public offer at price $c_{2}$.

In stage 2 , each downstream firm accepts the secret offer and $U_{1}$ is also chosen as an official supplier.

In stage 3 , all the firms propose a price equal to $p_{c_{1}}^{m}$.

In stage 4 , the division of the market is as follows. Firm $U_{1}$ sells a quantity $\frac{1+(N-1) \varepsilon}{N} q_{c_{1}}^{m}$ an all the other downstream firms sell a quantity equal to $\frac{1-\varepsilon}{N} q_{c_{1}}^{m}$.

For the time being, assume that after a deviation from this collusive agreement, there is an optimal punishment such that the deviator gets zero profit in all the remaining periods of the game (we will prove this later on). Now, if a firm deviates from the collusive agreement, it can propose a price arbitrarily close to $p_{c_{1}}^{m}$ and sell a quantity arbitrarily close to $q_{c_{1}}^{m}$. If $U_{1}$ makes such a deviation, it will obtain a profit arbitrarily close to $\pi_{c_{1}}^{m}$. If another downstream firm makes such a deviation, it will buy the first $\frac{1-\varepsilon}{N} q_{c_{1}}^{m}$ units of the intermediate good at price $c_{1}$ and the other units at a price higher or equal than $c_{2}$ so that its deviation profit is strictly smaller than $\pi_{c_{1}}^{m}-\frac{N-1+\varepsilon}{N} q_{c_{1}}^{m}\left(c_{2}-c_{1}\right)$ and the firm prefers not to deviate if

$$
\frac{\frac{1-\varepsilon}{N} \pi_{c_{1}}^{m}}{1-\delta} \geq \pi_{c_{1}}^{m}-\frac{N-1+\varepsilon}{N} q_{c_{1}}^{m}\left(c_{2}-c_{1}\right)
$$

If we denote $K=\frac{N-1+\varepsilon}{N} q_{c_{1}}^{m}\left(c_{2}-c_{1}\right)>0$, this condition can be rewritten:

$$
\delta \geq 1-\frac{1}{N} \frac{1-\varepsilon}{1-\frac{K}{\pi_{c_{1}}^{m}}}
$$

Since $K>0$, there exists an $\varepsilon$ sufficiently small such that $\frac{1-\varepsilon}{1-\frac{K}{\pi_{c_{1}}^{m}}}>1$ so that:

$$
1-\frac{1}{N} \frac{1-\varepsilon}{1-\frac{K}{\pi_{c_{1}}^{m}}}<1-\frac{1}{N}=\delta^{N I}
$$

Now, if firm 1 deviates, it can obtain a profit arbitrarily close to $\pi_{c_{1}}^{m}$ so that it prefers not to deviate if

$$
\frac{\frac{1+(N-1) \varepsilon}{N} \pi_{c_{1}}^{m}}{1-\delta} \geq \pi_{c_{1}}^{m}
$$

equivalent to 


$$
\delta \geq 1-\frac{1}{N}-\frac{N-1}{N} \varepsilon
$$

With $1-\frac{1}{N}-\frac{N-1}{N} \varepsilon<\delta^{N I}$.

Eventually, we need to build an equilibrium such that after a deviation by any firm, the continuation payoff of the deviating firm will be equal to zero.

We can easily build equilibrium strategies such that if $D_{j}$ with $j \neq 1$ deviates from the collusive behavior, its profit in all the following periods is equal to zero. For instance, this is the case if, after such a deviation, $U_{1}$ and $U_{2}$ and all the downstream firms propose a price equal to $c_{2}$ in all the posterior periods (assuming, for instance, that $U_{1}$ sells all the units). We can also propose equilibrium strategies such that $I_{1}$ 's continuation payoff is equal to zero after a deviation, thus ensuring maximal punishment also to the integrated firm. Suppose that, after a deviation by $I_{1}$, in all the posterior periods, $p_{1}=p_{2}=c_{1}$ and $\forall j>2, p_{j}>c_{1}$ for any value of the vector $\left(w_{1}, \ldots, w_{M}\right)$ and the equilibrium allocation rule is such that $D_{1}$ sells a quantity $Q\left(c_{1}\right)$ of the final good and $D_{2}$ sells zero unit of the final good. Without even specifying the value of $\left(w_{1}, \ldots, w_{M}\right)$, in this equilibrium, all the players obtain a continuation payoff equal to zero.

Q.E.D.

\section{Appendix A2: Proof of Proposition 2}

Let us consider the following collusive agreement.

In stage $1, U_{1}$ makes a secret proposal to other downstream firms, selling to each of them a quantity $\frac{1-\alpha}{N-1} Q\left(p^{c o l}\right)$, with $\alpha \in(0,1)$, and $p^{c o l} \in\left(c_{2}, p_{c_{1}}^{m}\right)$ at a price $c_{1}$ and a public offer at price $c_{2}$.

In stage 2 , each downstream firm accepts the secret offer and $U_{1}$ is also chosen as an official supplier.

In stage 3 , all the firms propose a price equal to $p^{\text {col }}$.

In stage 4 , the division of the market is as follows. Firm $U_{1}$ sells a quantity $\alpha Q\left(p^{c o l}\right)$ an all the other downstream firms sell a quantity equal to $\frac{1-\alpha}{N-1} Q\left(p^{c o l}\right)$.

Again, let us assume that after a deviation by any firm, its continuation profit in the following periods is equal to zero (we will go back to this issue later on).

$I_{1}$ 's collusive profit is $\frac{\alpha Q\left(p^{c o l}\right)\left(p^{c o l}-c_{1}\right)}{1-\delta}$ and its maximum deviation profit is arbitrarily close to $Q\left(p^{c o l}\right)\left(p^{c o l}-c_{1}\right)$ so that a deviation is not profitable for $I_{1}$ as long as $\delta>1-\alpha$. 
The collusive profit of firm $j$ with $j \neq 1$ is

$$
\frac{(1-\alpha) Q\left(p^{c o l}\right)\left(p^{c o l}-c_{1}\right)}{N(1-\delta)}
$$

And its deviation profit is arbitrarily close to:

$$
\frac{(1-\alpha) Q\left(p^{c o l}\right)\left(p^{c o l}-c_{1}\right)}{N}+\left(1-\frac{1-\alpha}{N}\right) Q\left(p^{c o l}\right)\left(p^{c o l}-c_{2}\right)
$$

So that a deviation is not profitable for $D_{i}$ as long as

$$
\delta>\left(\frac{N-1+\alpha}{1-\alpha} \frac{p^{c o l}-c_{2}}{p^{c o l}-c_{1}}\right) /\left(1+\frac{N-1+\alpha}{1-\alpha} \frac{p^{c o l}-c_{2}}{p^{c o l}-c_{1}}\right)
$$

This value tends towards zero when $p^{\text {col }}$ tends towards $c_{2}$, for any strictly positive value of $\alpha$. Then, as $p^{c o l}$ becomes closer to $c_{2}$, it is possible to raise $\alpha$ closer to 1 so that both $I_{1}$ and the other downstream firms prefer cooperating than deviating in a collusive equilibrium with a collusive price $p^{\text {col }}$ for any strictly positive value of $\delta$.

Now, regarding continuation payoffs after a deviation, we can use exactly the same arguments as in proof of Proposition 1 in order to prove that it is possible to define an equilibrium such that after a deviation by any firm, its continuation payoff is equal to zero.

Q.E.D.

\section{Appendix A3: Proof of Proposition 3}

To prove Proposition 3 we have to show that the maximum collusive price is decreasing in $\delta$. Let us consider a $\hat{\delta}<\delta^{I}$ and $\hat{p}$ the maximum collusive price that can be sustained with $\delta=\hat{\delta}$. We intend to prove that for a $\delta>\hat{\delta}$, it is possible to sustain a collusive equilibrium with a price strictly higher than $\hat{p}$.

First, by definition of $\delta^{I}$, we know that $\hat{p}<p_{c_{1}}^{m}$.

Second, following the same continuation strategies as the one we mentioned in the proof of Proposition 1, we know that it is possible to build equilibrium continuation payoffs such that the deviating firm obtains zero profit after the deviation so that for any firm $i$ :

$$
\frac{\alpha_{i}\left(\hat{p}-c_{1}\right) Q(\hat{p})}{1-\hat{\delta}} \geq \pi_{i}^{d}(\hat{\delta}, \hat{p})
$$

with $\alpha_{i}$ the share of the collusive profit obtained by firm $i$ and $\pi_{i}^{d}(\hat{\delta}, \hat{p})$, the maximum profit that firm $i$ can obtain by deviating from the collusive behavior. 
Now, let us consider the situation with a discount factor $\tilde{\delta}>\hat{\delta}$. Suppose that firms follow the same behavior as in a collusive equilibrium with discount factor $\hat{\delta}$ and a collusive price $\hat{p}$. From the previous inequality, we derive that for any firm $i$ :

$$
\frac{\alpha_{i}\left(\hat{p}-c_{1}\right) Q(\hat{p})}{1-\tilde{\delta}}>\pi_{i}^{d}(\hat{\delta}, \hat{p})
$$

Then, by a continuity argument, we know that it exists a $\tilde{p} \in\left(\hat{p}, p_{c_{1}}^{m}\right)$ such that, for any firm $i$ :

$$
\frac{\alpha_{i}\left(\tilde{p}-c_{1}\right) Q(\tilde{p})}{1-\tilde{\delta}}>\pi_{i}^{d}(\tilde{\delta}, \tilde{p})
$$

Again,we know that, for any collusive agreement, it is possible to build equilibrium continuation payoffs such that the deviating firm obtains zero profit after the deviation. Therefore, this inequality ensures that when the discount factor is equal to $\tilde{\delta}$, there exists a collusive equilibrium with a price $\tilde{p}$ strictly higher than $\hat{p}$.

Q.E.D. 